Klinik Araştırma / Clinical Research

\title{
Endokrin hastalıklarda deri bulguları
}

\section{Cutaneous manifestations of endocrine disorders}

\author{
Nursel Dilek*a ${ }^{* a}$ unus Saral ${ }^{\mathrm{b}}$ Ramis Çolak $^{\mathrm{c}}$ \\ ${ }^{a}$ Rize Ĕ̈itim Araştırma Hastanesi, Dermatoloji, Rize \\ ${ }^{b}$ Rize Üniversitesi, Tip Fakültesi, Dermatoloji Anabilim Dalı, Rize \\ 'Ondokuz Mayıs Üniversitesi, Tıp Fakültesi, Endokrinoloji Bilim Dalı, Samsun
}

\begin{tabular}{|c|c|}
\hline MAKA & GİLERİ \\
\hline Maka & \\
\hline Geliş̧ & $22 / 12 / 2010$ \\
\hline Kabul & $23 / 12 / 2010$ \\
\hline
\end{tabular}

\section{* Yazışma Adresi:}

Nursel Dilek

Rize Eğitim Araştırma Hastanesi

Dermatoloji, Rize

e-posta: nur.dilek@hotmail.com

\section{Anahtar Kelimeler:}

Dermatolojik bulgular

Yaş

Cinsiyet

Endokrin hastalıklar

Dermatolojik muayene

Endokrin hormonlar

\section{Keywords:}

Cutaneous Manifestations

Age

Sex

Endocrine disorders

Dermatologic examination

Endocrine hormones

\section{ÖZET}

Birçok endokrin hastalı̆̆ın seyri sırasında deri bulguları olabilmektedir. Bu deri lezyonlarının tanınması endokrin hastalıkların teşhisinde ve tedavisinde çok önemli bir yere sahiptir. Bu çalışmada endokrin hastalığı tanısı almış olan 272 hastanın dermatolojik hastalıkların sıklı̆̆ının belirlenmesi, aynı hastalardaki dermatolojik bulguların ve semptomların yaş ve cinsiyete göre dağılımının araştırılması amaçlanmıştır. Çalışmaya 203'ü kadın 69'u erkek toplam 272 hasta alındı. Yapılan istatistiksel analiz sonucunda endokrin hastalıkların hastaların yaş ve cinsiyetlerine göre dağılımında anlamlı farklılıklar bulundu $(\mathrm{p}<0.00)$. Hastaların yapılan muayenelerinde 94 'ünde $(\% 34,6)$ saç hastalığı, 80'inde $(\% 29,4)$ tırnak hastalığ 1 , 48'inde $(\% 17,6)$ deri enfeksiyonu, 43'ünde $(\% 15,8)$ kronik güneş hasarı, 36'sında $(\% 13,2)$ keratozis pilaris, 61'inde $(\% 22,4)$ akne vulgaris, 74 'ünde $(\% 27,2)$ kseroderma, 83 'ünde $(\% 30,5)$ pruritus, 61'inde $(\% 22,4)$ skin tag ve 28 'inde $(\% 10,3)$ akantozis nigrikans mevcuttu. Deri enfeksiyonların yaşla birlikte arttığ $(p<0,00)$ ve 4 . dekatta en fazla olduğu, tırnak hastalıklarının da yaşla birlikte arttığı belirlendi $(\mathrm{p}<0,00)$. Ancak, acne vulgarisin erken yaşlarda fazla olduğu, ileri yaşlarda azaldığ belirlendi $(\mathrm{p}<0,00)$. Akne vulgaris tanısı alanların ağırlıklı olarak hirsutismus grubunda olması istatistiksel olarak anlamlı bulundu $(p<0,00)$. Elde ettiğimiz bu veriler sonucunda endokrin hastaların düzenli olarak dermatolojik muayenelerinin yapılması gerektiği kanaatine varılmıştır.

J. Exp. Clin. Med., 2011; 28:45-48

\begin{abstract}
During the course of endocrine diseases, skin symptoms may be seen. Recognition of endocrin skin lesions have very important role in the diagnosis and treatment of endocrine diseases. In this study, we aimed to investigate the frequency of dermatological diseases and distribution of dermatological signs and symptoms according to age and sex in 272 patients diagnosed with endocrine disease. Total 272 patients were included in the study; 203 women, 69 men. Significant differences were seen at result of the statistical analysis of endocrine diseases according to age and sex $(\mathrm{p}<0.00)$. In examination of patients 94 (34.6\%) hair disease, $80(29.4 \%)$ nail disease, 48 (17.6\%) skin infection, 43 (15.8\%) chronic sun damage, 36 (13.2\%) keratosis pilaris, 61 (22.4\%) acne vulgaris, 74 (27.2\%) xeroderma, $83(30.5 \%)$ pruritus, $61(22.4 \%)$ skin tag, 28 (10.3\%) acanthosis nigricans were seen. Increased incidence with age in skin infections (the greatest 4 . decade) and nail disease were seen $(p<0.00)$. However, acne vulgaris is more in early age than elderly $(p<0.00)$. Diagnosed patients with acne vulgaris were mainly in the fields of hirsutism group $(p<0.00)$. As a result of these data, dermatological examinations should be performed in endocrine disease patients regularly.

J. Exp. Clin. Med., 2011; 28:45-48
\end{abstract}

(C) 2011 OMU All rights reserved

\section{Giriş}

Endokrin fonksiyonlardaki patolojilerde ilk bulgular deride morfolojik ve fonksiyonel değişiklikler olarak görülebil- mekte ve deri lezyonları da birçok endokrin hastalığın önemli bulgusu olabilmektedir. Tanı koymada yol gösterici olan bu lezyonların tanınması endokrin hastalıkların erken teşhis ve 
tedavisi için çok önemlidir (Jordan ve ark., 2006; Batya ve ark., 2008).

Deri hastalıklarına yol açabilen endokrinopatiler arasında hipertroidi, hipotroidi, Cushing hastalığı, Addison hastalığ1, akromegali, hiperandrojenizm, hipopituitarizm, hiperparatroidizm gibi hastalıklar yer almaktadır. Endokrinopatilerde düzeltici tedaviden çok semptomatik tedavi verilebildiği için bu grup hastalıkların teşhis edilmesi çok önemlidir (Jabbour, 2003).

Tablo 1. Dermatolojik Bulguların Cisiyete Göre Dağılım

\begin{tabular}{|c|c|c|c|c|c|}
\hline & Bayan & \multicolumn{2}{|c|}{ Erkek } & \multirow[t]{2}{*}{ Toplam } & \multirow[b]{2}{*}{$\begin{array}{l}\text { İstatistik } \\
\mathrm{X}^{2}\end{array}$} \\
\hline & n $\%$ & n & $\%$ & & \\
\hline \multicolumn{6}{|c|}{ Sac Hastalıkları } \\
\hline Yok & 12168,0 & 57 & 32,0 & 178 & $p=0,001$ \\
\hline Var & 8287,2 & 12 & 12,8 & 94 & \\
\hline \multicolumn{6}{|c|}{ Tırnak Hastalıkları } \\
\hline Yok & 15178,6 & 41 & 21,4 & 192 & $\mathrm{p}=0,018$ \\
\hline Var & 5265,0 & 28 & 35,0 & 80 & \\
\hline \multicolumn{6}{|c|}{ Deri Enfeksiyonları } \\
\hline Yok & 18281,3 & 42 & 18,8 & 224 & $p=0,0001$ \\
\hline Var & 2143,8 & 27 & 56,3 & 48 & \\
\hline \multicolumn{6}{|c|}{ Skin Tag } \\
\hline Yok & 15372,5 & 58 & 27,5 & 211 & $\mathrm{p}=0,135$ \\
\hline Var & 5082,0 & 11 & 18,0 & 61 & \\
\hline \multicolumn{6}{|c|}{ Kronik Güneş Hasarı } \\
\hline Yok & 17476,0 & 55 & 24,0 & 229 & $\mathrm{p}=0,238$ \\
\hline Var & 2967,4 & 14 & 32,6 & 43 & \\
\hline \multicolumn{6}{|c|}{ Keratozis Pilaris } \\
\hline Yok & 17674,6 & 60 & 25,4 & 236 & $p=0,957$ \\
\hline Var & 2775,0 & 9 & 25,0 & 36 & \\
\hline \multicolumn{6}{|c|}{ Akne Vulgaris } \\
\hline Yok & 14970,6 & 62 & 29,4 & 211 & $p=0,005$ \\
\hline Var & 5488,5 & 7 & 11,5 & 61 & \\
\hline \multicolumn{6}{|c|}{ Kseroderma } \\
\hline Yok & 15477,8 & 44 & 22,2 & 198 & $p=0,051$ \\
\hline Var & 4966,2 & 25 & 33,8 & 74 & \\
\hline \multicolumn{6}{|c|}{ Pruritus } \\
\hline Yok & 13873,0 & 51 & 27,0 & 189 & $p=0,355$ \\
\hline Var & 6578,3 & 18 & 21,7 & 83 & \\
\hline \multicolumn{6}{|c|}{ Akantozis Nigrikans } \\
\hline Yok & 18274,6 & 62 & 25,4 & 244 & $p=0,962$ \\
\hline Var & 2175,0 & 7 & 25,0 & 28 & \\
\hline
\end{tabular}

$\mathrm{Bu}$ çalışmada endokrin hastalığı tanısı almış olan hastalardaki dermatolojik hastalıkların sıklığının belirlenmesi, aynı hastalardaki dermatolojik bulguların yaşa ve cinsiyete göre dağılımının araştırılması planlanmıştır.

\section{Araştırma Yöntemi}

Çalışmaya daha önce endokrin hastalığı teşhisi konmuş olan 272 hasta alındı. Hastaların yaşları, cinsiyetleri, endokrin hastalıkları ve hastalıkların süreleri, hasta formlarına kaydedildi. Tüm hastaların dermatolojik muayeneleri yapılarak elde edilen bulgular kayıt altına alındı.

Çalışmaya alınan hastaların endokrin hastalıkları hipertroidi, hipotroidi, akromegali, Cushing Sendromu, panhipopituitarizm, hiperprolaktinemi, Addison Hastalığı, hirsutismus ve diğerleri (feokromasitoma, obesite, büyüme gelişme geriliği, hipogonadizm, amenore, diabetes insipitus, hiperparatoidi, osteoporoz ve insülinoma) olarak sinıflandırıld1.Dermatolojik muayene sonucunda elde edilen bulgular on grupta topland1. Bunlar; saç hastalıkları (tellogen efflivium, kuru ve kaba saç), tırnak hastalıkları (onikoreksis, onikolizis, subungual hiperkeratoz, pitting, paroniş), deri enfeksiyonları (fronkül, karbonkül, impetigo, eritrazma, yüzeyel herpes enfeksiyonları, yüzeyel dermatofit ve yüzeyel kandida enfeksiyonları), skin tag, kronik güneş hasarı (lentigo solaris, aktinik keratoz, seboreik keratoz), keratozis plaris, akne vulgaris, kserozis kutis, pruritus ve akantozis nigrikans olarak belirlendi.
Elde edilen veriler bilgisayar ortamında SPSS 13,0 istatistik programı kullanılarak değerlendirildi. Grupların değerlendirilmesinde ki-kare testi uygulandı. Değerlendirmede $\mathrm{p}<0,05$ anlamlı kabul edildi.

\section{Sonuçlar}

Çalışmaya yaşları 17-71 $(40 \pm 14)$ yıl arasında değişen, 203'ü kadın 69'u erkek toplam 272 hasta alındı. Yapılan istatistiksel analiz sonucunda endokrin hastalıkların hastaların yaş ve cinsiyetlerine göre dağılımında anlamlı farklılıklar bulundu $(\mathrm{p}<0,00)$. Kadınlarda erkeklere göre ve ve 4. dekattaki hastalarda endokrin hastalıklar daha fazla olduğu belirlendi (Tablo 1 ve Tablo 2). Çalışmaya alınan hastaların 105'inde hipotroidi, 51'inde hipertroidi, 27'sinde hirsutismus, 14'ünde panhipopituitarizm, 9'unda akromegali, 9'unda hiperprolaktinemi 4'ünde Cushing Sendromu ve 7'sinde Addison Hastalığı tanısı bulunmaktaydı. Diğerleri olarak sınıflandırılan grupta 46 hasta bulunmaktaydi.

Hastaların yapılan muayenelerinde 94'ünde $(\% 34,6)$ saç hastalığı, 80'inde $(\% 29,4)$ tırnak hastalığı, 48'inde $(\% 17,6)$ deri enfeksiyonu, 43'ünde $(\% 15,8)$ kronik güneş hasarı, 36'sında $(\% 13,2)$ keratozis pilaris, 61 'inde $(\% 22,4)$ akne vulgaris, 74 'ünde $(\% 27,2)$ kseroderma, 83 'ünde (\%30,5) pruritus, 61 'inde $(\% 22,4)$ skin tag ve 28 'inde (\%10,3) akantozis nigrikans mevcuttu (Tablo 3). Diğer deri hastalıklarının her iki cinsiyet arasında farklılıkları bulunamadı. Endokrin hastalarda yapılan dermatolojik muayene sonucunda elde edilen verilerden kronik güneş hasarı ve kserodermanın yaşla birlikte $\operatorname{arttığ~}_{1}($ sırasıyla $\left.\mathrm{p}<0,00), \mathrm{p}<0,00\right)$ belirlendi. Deri enfeksiyonların yaşla birlikte $\operatorname{arttığ~}(p<0,00)$ ve 4. dekatta en fazla olduğu, tırnak hastalıklarının da yaşla birlikte arttığ belirlendi $(\mathrm{p}<0,00)$. Ancak, acne vulgarisin ileri yaşta azaldığı belirlendi $(\mathrm{p}<0,00)$. Saç hastalıkları, skin tag, keratozis pilaris, piruritus ve akantozis nigrigansın yaşla ilişkisi bulunmamaktaydı (Tablo 2).

Tablo 2. Dermatolojik BulgularınYaşa Göre Dağılımı

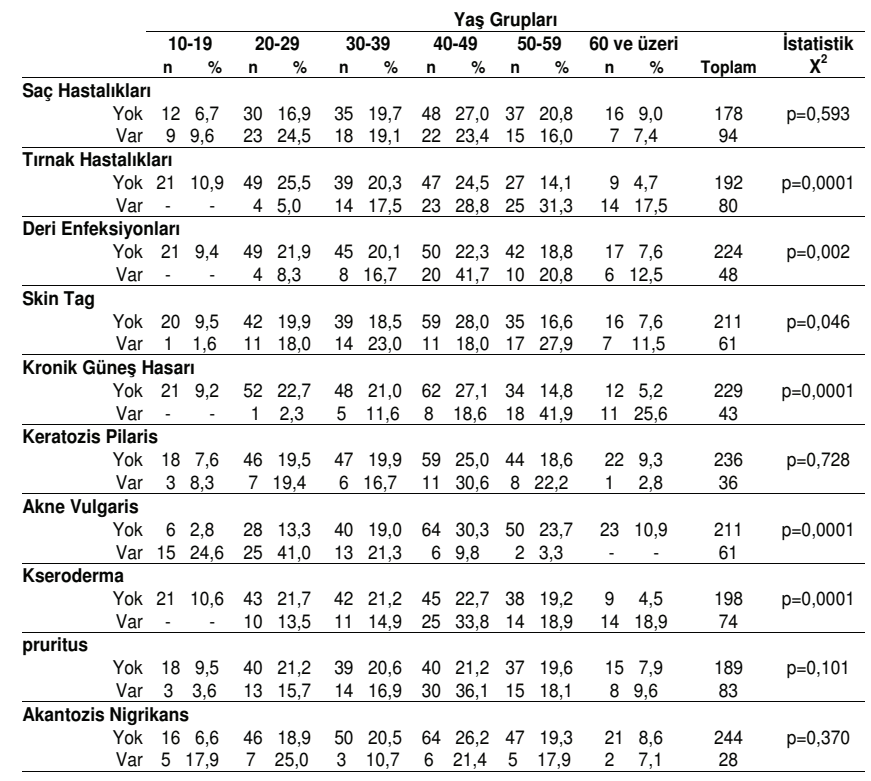

Akne vulgaris tanısı alanların ağırlıklı olarak hirsutismus grubunda olması istatistiksel olarak anlamlı bulundu $(\mathrm{p}<0,00)$. Endokrin hastalıklarda saç hastalıkları, tırnak hastalıkları, deri enfeksiyonları, kronik güneş hasarı, keratozis pilaris, kseroderma, piruritus ve akantozis nigrigansın sıkl1ğında anlamlı fark bulunmamaktayd. 
Tablo 3. Dermatolojik bulguların Dağılımı

\begin{tabular}{lcc}
\hline $\begin{array}{l}\text { Dermatolojik Bulgular } \\
\text { (DB) }\end{array}$ & $\begin{array}{c}\text { DB + Olanlar } \\
\mathbf{n}\end{array}$ & $\begin{array}{c}\text { DB-Olanlar } \\
\text { \% }\end{array}$ \\
\hline Saç Hastalıkları & 94 & 34,6 \\
Tirnak Hastalıkları & 80 & 29,4 \\
Deri Enfeksiyonları & 48 & 17,6 \\
Kronik güneş Hasarı & 43 & 15.8 \\
Skin Tag & 61 & 22.4 \\
Keratozis Pilaris & 36 & 13,2 \\
Akne Vulgaris & 61 & 22,4 \\
Kseroderma & 74 & 27,2 \\
Pruritus & 83 & 30,5 \\
Akantozis Nigrikans & 28 & 10,3 \\
\hline n toplam: 272 \%'ler satır yüzdesidir
\end{tabular}

n toplam: 272, \%'ler satır yüzdesidir

\section{Tartışma}

Hormonlar derinin gelişiminde ve fizyolojik fonksiyonunda önemli rol oynar (Zouboulis, 2004). Hormonların üretimindeki farklılıklar; metabolizma, kan basınc1, seksüel fonksiyonlar, üreme, büyüme, süt salınımı ve vital fonksiyonlar üzerinde önemli etkiye sahiptir (Davidovic ve ark., 2008). Hormon düzeyindeki değişikliklerle ortaya çıkan deri reaksiyonları, deride farklı düzeyde bulunan hormon spesifik reseptörler tarafından kontrol edilir. Ayrıca vasküler kanlanma, travma, enfeksiyonlar ve ultraviyoleye maruziyet de hormonlara verilen cevapta etkilidir (Braun-falco ve ark., 2009).

Hipofiz bezi su homeostası, metabolizma, büyüme ve üreme gibi diğer endokrin bezlerin ve fizyolojik durumların kontrolünü sağlayan bir yönetici olarak görev yapmaktadır. Hipopituitarizm gibi bir veya daha fazla hormonun kısmi veya tam yokluğunda deriye ait yapılarda saç, tırnaklar, epidermis, dermis, pigmentasyon, ekrin ve sebase bezlerde değişiklikler ortaya çıkar. Hipopituitarizme bağlı gelişen klinik durumların çeşitliliği yaşa, patolojinin başlangıç hızına, hormonların etki alanlarına ve eksikliğin derecesine bağlıdır. Özellikle yaşl1 hastalarda, endokrin organların hipo-hipersekresyonunda spesifik bulgular ortaya çıkar (Geller ve Braunstei, 2006). Bizim hastalarımız içerisinde kseroderma, kronik güneş hasarı ve deri enfeksiyonları yaşlı hastalarda daha fazlayken akne genç hastalarımızda fazlaydı.

Growth hormon (GH) bedensel büyümeyi, vücuttaki protein ve karbonhidrat metabolizmasındaki regülasyonu sağlayan hipofizer bir hormondur (Melmed ve Kleinberg, 2003; Geller ve Braunstei, 2006). GH eksikliği çocuklarda orantılı vücut kısalığına neden olur ve genellikle hayatın 12 . ve 18 . aylarında teşhis edilir (Cummings ve Merriam, 2003). GH eksikliğinde epidermisin inceldiği gözlenir. Ekrin ter bezleri küçülür, sayıları azalır, morfolojisi ve elastin fibrillerin konfigürasyonunda değişiklik olur (Lange ve Feldt-Rasmussen, 2001; Geller ve Braunstei, 2006).

GH fazlalığında ise deri kaba ve kalındır. Hastalarda sivri çene, frontal çıkıntı, seyrek dişler, alt dudak sarkık ve kalındır, ayrıca ödemli göz kapağı mevcuttur. Dermis kalınlığının artmasına bağlı olarak saçlı deride kutis vertisis girata meydana gelebilir (Davidovic ve ark., 2008).

Troid hormonlarından T4 hem epidermal büyüme faktörünün üretimini hemde epidermal büyüme faktörün reseptörüne afinitesini artırır. T3 ise epidermal turnoveri regüle eder ve keratinosit diferansiyasyonunu sağlar. Bu hormonların yokluğunda deri kuru, kaba, skuamlı bir görünüm kazanır. Sebase, ekrin ve apokrin bez sekresyonları azalır, tırnaklar kuru ve kırılgandır (Jabbour ve Mille, 2000; Leonhardt ve
Heymann, 2002; Geller ve Braunstei, 2006). Troid hastallklarında egzoftalmus, pretibial miks ödem gibi direkt hastalığa bağlı oluşan deri bulgularının yanı sıra, otoimmün troid hastalığına yatkın olanlarda vitiligo, liken skleroz atrofikus gibi deri hastalıkları da görülebilir (Kirby ve James, 2008).

Hipotroidili hastaların yarısından fazlasında saç siklusunun anagen fazında bozulma olur, anagen fazdaki saçlarda kayıp ve generalize alopesi gelişir. Kaşlar diş lateralden dökülür, saçlar kuru, kaba ve kırılgan hale gelir. Hormon replasmanıyla telogen saçlar artar.

Hipotroidizmde epidermiste $\beta$ karoten birikimi olur. Palmoplantarda ve nazolabial katlantılarda sarı renge neden olur ve sarılıktan skleraların tutulmamasıyla ayırdedilebilir. Metabolizmanın yavaşlaması ve refleks kutanöz vazokonstriksiyon nedeniyle hastalar soluk görünür. Bu hastalarda dermiste su ve mukopolisakkaridoz birikir, bu birikim 1şığın yansımasın1 değiştirir, hastalar soluk görünür (Jabbour ve Mille, 2000; Leonhardt ve Heymann, 2002; Geller ve Braunstei, 2006).

Sex hormonları keratinositlerin büyümesini ve melanosit aktivitesini stimüle eder. Östrojen eksikliği deride kuruluğa, kaşıntıya ve atrofiye neden olur. Çünkü östrojen bağım11 hiyalüronik asit üretimi azalmasının yanı sıra, sebase ve ekrin bezlerin üretimi de azalmıştır. Östrojen ve androjenler kollajenin sentezini, matürasyonunu ve turnoverini sağlar. Östrojen aracılı kollajen ve elastin matürasyon ve sentez eksikliğinde deri kuru, ince ve esnekliğini yitirmiştir. Androjen bağımlı kollajen sentez ve matürasyon eksikliğinde ise deri ve subkütan doku incelir. Yüz çizgileri azalmıştır. Ağız ve göz çevresinde ince çizgilenmeler bulunur. Kadınlarda hiperandrojenemi geliştiğinde akne, hirsutismus ve virilizasyon bulguları ortaya çıkar (Jabbour, 2003; Geller ve Braunstei, 2006). Bizim çalışmamızdaki tüm hastalar içerisinde akne ve saç hastalıkları kadınlarda erkeklerden daha fazla bulunmaktaydi.

Glukokortikoidlerin eksikliğinin direkt deriye etkisi rapor edilmemiştir. Ancak anoreksi, bulantı ve kusmaya bağlı olarak adrenal yetersizlik meydana gelir, interstisyel sıvı kaybı nedeniyle hastada dehidratasyon bulguları gelişir (McGee ve ark., 1999; Geller ve Braunstei, 2006).

Cushing sendromu gibi glukokortikoidlerin fazlalığında ise atrofiye bağlı olarak el sırtında, dirseklerde sigara kağ1d1 görünümü oluşur. Ayrıca hastalarda poikiloderma benzeri lezyonlar da bildirilmiştir (Geller ve Braunstei, 2006). Glukokortikoidlerin fazlalığına bağlı oluşan tipik lezyon, özellikle gövde yerleşimli geniş, mor strialardır. Hormonal patoloji düzeldiğinde striaların rengi düzelirken atrofi kalıcıdır. Cushing hastalığında ACTH fazlalığı nedeniyle hiperpigmentasyon meydana gelebilir. Pigmentasyon genellikle diffüz olmakla birlikte özellikle güneş gören yerlerde daha fazla olur. Kronik travma ve basiya maruz kalan yerlerdeki pigmentasyon daha fazla dikkat çeker. Akantozis nigrikans meydana gelebilir. Yüzde genişleme ve telenjiektaziler olabilir. Hipertrikoz ve akne genellikle vardır. Akne lezyonları uniformdur, komedon ve kist genellikle yoktur. Hipertrikozda kıllar lanuga şeklindedir ve çeneye, üst dudak bölgesine lokalizedir. Santral obesite görülür (Thody ve Graham, 1998; Vaudry ve ark., 1999; Slominski ve ark., 2000; Kauser, ve ark., 2005; Geller ve Braunstei, 2006).

ACTH'nın prekürsörü olan proopiomelanokortin, aynı zamanda $\alpha$-melanosit-stimulating hormonun $(\alpha-\mathrm{MSH})$ kaynağıdır. $\alpha-M S H$ ve ACTH'nın her ikiside MC-1R ve MC-2R reseptörlerine bağlanarak deri pigmentasyonunda rol oynar. 
Hipofizer ACTH eksikliğinde hipopigmentasyon meydana gelir. Hastalarda özellikle genital, meme areolası ve yüzde olmak üzere diffüz solukluk oluşur. Deri turgoru azalır, deri kurur, kadınlarda aksiller ve pubik kıllarda azalma olur (Jabbour ve Mille, 2000; Darzy ve Shalet, 2003; Melmed ve Kleinberg, 2003).

Androjenler, GH, IGF-1, insülin ve glukokortikoidler akne gelişimine etkili hormonlardandır. Polikistik over hastalığ1, akromegali, Cushing hastalığı, androjen sekrete eden tümörler gibi endokrin hastalıklarda akne gelișimi artar (Lolis ve ark., 2009). Bizim çalışmamızda da hirsutismuslu hasta grubunda akne anlamlı bir şekilde fazla bulunmuştur. Tüm endokrin hastalar arasında saç hastalıklarından $(\% 52,8)$ ve tırnak hastalıklarından $(\% 41,6)$ sonra en sık tesbit ettiğimiz dermatolojik bulgu kseroderma $(\% 37,3)$ ve pruritus $(\% 43,9)$ idi.

Sonuç olarak endokrin hastalarda deri bulguları azımsanmayacak kadar çok görülmektedir. Dikkatli dermatolojik muayenenin endokrin patolojilerin erken teşhisinde ve daha önce endokrin hastalık tanısı konmuş olanların ise tedavisinde katkısının olacağı bu nedenle tüm endokrin hastalığı olan hastaların belli periyotlarla dermatolojik muayenelerinin yapılmasının gerektiği kanaatindeyiz.

\section{KAYNAKLAR}

Braun-falco, O., Plewing, G., Wolff, H.H., Burgdorf, W.H.C. 2009. Endocrine Diseases Luger, T, Böhm, M. Dermatology. 3. edtion, Berlin: Springer Medizin Verlag Heidelberg Italy, pp. 1312-1324.

Cummings, G.E., Merriam, G.R. 2003. Growth hormone therapy in adults. Annu Rev. Med. 53, 513- 533.

Darzy, K.H., Shalet, S.M. 2003. Radiation-induced growth hormone deficiency. Horm Res. 59, 1 - 11.

Davidovic, B.B., Orion, E., Wolf, R. 2008. Cutaneous manifestations of pituitary gland diseases. Clin. Dermatol. 26, 288-295.

Geller, J.L., Braunstei, G.D. 2006. Dermatologic manifestations of hypopituitarism. Clin. Dermatol. 24, 266- 275.

Jabbour, S.A. 2003. Cutaneous manifestations of endocrine disorders: a guide for dermatologists. Am. J. Clin. Dermatol. 4, 315-331.

Jabbour, S.A., Mille, J.L. 2000. Endocrinopathies and the skin. Int. J. Dermatol. 39, 88- 99.

Kauser, S., Thody, A.J., Schallreute, K,U. 2005. A fully functional proopiomelanocortin/ melanocortin-1 receptor system regulates the differentiation of human scalp hair follicle melanocytes. Endocrinology. 146, 532- 543.

Kirby, J.S., James, W.D. 2008, Dermatologic Disorders Associated with Thyroid Disease. Heymann, W.R. Thyroid Disorders with Cutaneous Manifestations Springer-Verlag London Limited. P. 157-179.

Lange, M., Feldt-Rasmussen T.J. 2001. Skin morphological changes in growth hormone deficiency and acromegaly. Eur. J. Endocrinol. 145, $147-153$.

Leonhardt, J.M., Heymann, W.R. 2002. Thyroid disease and the skin. Dermatol. Clin. 20, 473 - 481.

Lolis, MS., Bow, W.P., Shalita, A.R. 2009. Acne and systemic disease. Med. Clin. North Am. Nov. 93, 1161-1181.

McGee, S., Abernethy, W.B., Simel, D.L. 1999. The rational clinical examination.this patient hypovolemic. JAMA. 281,1022 - 1029.

Melmed, S., Kleinberg, D. 2003, Anterior pituitary. In: Larson PR, Kronberg HM, Melmed S, Polonsky KS, editors. Williams textbook of endocrinology. 10th ed. Philadelphia/ Elsevier Science, p. 177- 280.

Slominski, A., Wortsman, J., Luger, T., Paus, R., Salomon, S. 2000. Corticotropin releasing hormone and proopiomelanocortin involvement in the cutaneous response to stress. Physiol. Rev. 80, 979- 1020.

Thody, A.J., Graham, A. 1998. Does alpha-MSH have a role in regulating skin pigmentation in humans? Pigment Cell Res. 11, 265 - 274.

Vaudry, H., Chartrel, N., Desrues, L. 1999. The pituitary-skin connection in amphibians. Reciprocal regulation of melanotrope cells and der mal melanocytes. Ann N Y Acad. Sci. 885, 41 - 56.

Zouboulis, C.C. 2004. The human skin as a hormone target and an endokrine gland. Hormones. 3, 9-26. 